\title{
A comparison of the multiple alleles of $x y l S$ carried by TOL plasmids pWW53 and pDK1 and its implications for their evolutionary relationship
}

\author{
Susan J. Assinder, Paolo De Marco $\uparrow$ David J. Osborne, $\ddagger$ Chit laa Poh, $\S$ Linda E. Shaw, \\ Michael K. Winson\| and Peter A. Williams* \\ School of Biological Sciences, University of Wales, Bangor, Gwynedd LL57 2UW, Wales, UK
}

(Received 26 June 1992; revised 18 September 1992; accepted 2 November 1992)

\begin{abstract}
Both of the independently isolated TOL plasmids pWW53 and pDK1 contain multiple regions homologous to the $x y l S$ regulatory gene of the archetypal TOL plasmid pWW0. The three homologues on pWW53 vary in the extent of their homology to $x y l S_{\mathrm{pww} 0} . x y l S 1_{\mathrm{pww} 3}$ is $99 \%$ identical to $x y l S_{\mathrm{pww} 0}$ and is located relative to the single copy of $x y l R_{\mathrm{pWw} 53}$ in exactly the same way as $x y l S$ and $x y l R$ on pWW0. The DNA sequence of $x y l S 3_{\mathrm{pWw} 53}$ is $87 \%$ identical to the $x y l S_{\mathrm{pww}}$ sequence within the coding region but the non-coding DNA upstream is not homologous. There is a frame-shift change at the end of the coding region which causes the $\mathrm{C}$ terminus of $\mathrm{XyIS}_{\mathrm{pwws}_{3}}$ to be extended by an additional 10 amino acids relative to $\mathrm{XylS}_{\mathrm{pww} 0^{*}} x y l S 2_{\mathrm{pww} 3}$ is anomalous and appears to encode a truncated pseudogene lacking the first 525 bases found in the other $x y l S$ genes. Evidence is presented to show that both $x y l S 1_{\mathrm{pww} 53}$ and $x y l S 3_{\mathrm{pww} 53}$ act as regulators of meta pathway operons. Plasmid pDK1 carries two homologues of $x y l S . x y l S 1_{\mathrm{pDK} 1}$ is functional and is a hybrid gene: its $5^{\prime}$ end and the upstream sequences are highly homologous to both $x y l S 1_{\mathrm{pww} 53}$ and $x y l S_{\mathrm{pww} 0}$, whereas its $3^{\prime}$ end is identical to $x y l S 3_{\mathrm{pww} 53}$. The sequence of $x y l S 2_{\mathrm{pDK} 1}$ is identical to that of the anomalous truncated $x y l S 2_{\mathrm{pww} 53^{\circ}}$ Comparison of the organization and the restriction maps of the $x y l$ catabolic operons on pDK1 and pWW53, together with the nucleotide sequences presented here, indicates that the catabolic DNA on pDK1 has derived from a replicon on which the $x y l$ genes are organized similarly to pWW53 and that a genetic rearrangement has taken place involving a reciprocal recombination internal to two of its $x y l S$ homologues.
\end{abstract}

\section{Introduction}

The molecular biology of the TOL pathway for the catabolism of toluene and the xylenes has been characterized in greatest detail on the $117 \mathrm{kbp}$ plasmid pWW0

*Author for correspondence. Tel. 0248 382363; fax 0248370731.

$\dagger$ Present address: Department of Biological Sciences, University of Warwick, Coventry CV4 7AL, UK.

$\ddagger$ Present address: Department of Molecular Biology and Biotechnology, University of Sheffield, Sheffield S10 2UH, UK.

$\S$ Present address: Department of Microbiology, Faculty of Medicine, National University of Singapore, Singapore 0511.

|| Present address: School of Agriculture, University of Nottingham, Sutton Bonnington, Leicestershire LE12 5RD, UK.

The nucleotide sequence data reported in this paper have been submitted to GenBank and have been assigned the accession numbers L02356 ( $\left.x y l S l_{\mathrm{pww53}}\right), \mathrm{L} 02643\left(x y l S 2_{\mathrm{pww} 3}\right), \mathrm{L} 02357$ ( $\left.x y l S 3_{\mathrm{pww} 33}\right)$, L02358 $\left(x y l S l_{\mathrm{pDK} 1}\right)$ and L02642 (xylS2 $\left.2_{\mathrm{pDK} 1}\right)$. from Pseudomonas putida mt-2. However, a number of other plasmids encoding the same catabolic functions have been reported (see Assinder \& Williams, 1990) and the gene organization on two, pWW53 (Keil et al., $1985 a, 1987 a, b$; Osborne et al., 1988) and pDK1 (Shaw \& Williams, 1988) has been described in some detail. This evidence suggests that the genetic organization of the $x y l$ catabolic genes found on pWW0 (Franklin et al., 1981), namely single operons for the upper pathway (Harayama et al., 1989), and the meta pathway genes (Harayama \& Rekik, 1990), is not typical of other TOL plasmids. Not only are the $x y l$ operons arranged in different orders and orientations but there is increasing evidence that many carry more than one copy either of whole operons or of individual genes (Keil et al., 1985b; Chatfield \& Williams, 1986; O'Donnell \& Williams, 1991). In particular we have shown that the $107 \mathrm{kbp}$ plasmid pWW53 carries two homologous, but distinguishable, direct repeats of the meta pathway operon $x y l X Y Z L T E G F J Q K I H$ both of which are functional (Osborne et al., 1988). In this paper we show the 
existence on two TOL plasmids of multiple copies of the $x y l S$ regulatory gene, responsible for the activation of the meta pathway operon by benzoate or methylbenzoates (toluates). Consideration of the nucleotide sequences, together with the overall $x y l$ gene organization, suggests that plasmid pDK1, which was isolated by Kunz \& Chapman (1981) in Minneapolis-St Paul, USA, appears to have derived from a major recombinational rearrangement from a plasmid similar in its $x y l$ gene organization to pWW53 which was independently isolated from the geographically distant location of Bangor, North Wales, UK.

\section{Methods}

Bacterial strains and plasmids. Bacterial strains and plasmids used are listed in Table 1. Bacteria were grown and maintained according to Worsey \& Williams (1975) and Keil et al. $(1985 a, b)$.

Table 1. Bacterial strains and plasmids

\begin{tabular}{|c|c|c|}
\hline Strain & Plasmid & Notes and reference \\
\hline \multicolumn{3}{|c|}{ Pseudomonas strains } \\
\hline \multicolumn{2}{|c|}{ PaW130 } & Keil et al. $(1985 b)$ \\
\hline MT53 & pWW53 & Keil et al. (1985a) \\
\hline MT53-1 & pWW53-1 & Osborne et al. (1988) \\
\hline MT53-2 & pWW53-2 & Osborne et al. (1988) \\
\hline HS1 & pDK1 & $\begin{array}{l}\text { Wild type isolate (Kunz \& Chapman, } \\
\text { 1981) }\end{array}$ \\
\hline PpCM1 & pDKM1 & $\begin{array}{l}\text { Benzoate-selected segregant of HS1 } \\
\text { (Kunz \& Chapman, 1981) }\end{array}$ \\
\hline \multicolumn{3}{|c|}{ Vector plasmids } \\
\hline & pUC18/pUC19 & Yanisch-Perron et al. (1985) \\
\hline & pKT230 & Bagdasarian et al. (1981) \\
\hline & pFBI. 1 & Pharmacia \\
\hline & pBR325 & Prentki \& Kirsch (1982) \\
\hline \multicolumn{3}{|c|}{ Recombinant plasmids from pWW53 } \\
\hline & pWW53-3002 & Osborne et al. (1988) \\
\hline & pWW53-3004 & Osborne et al. (1988) \\
\hline & pWW53-3508 & Keil et al. $(1987 b)$ \\
\hline & pWW53-3010 & $\begin{array}{l}6.7 \mathrm{kbp} \text { HindIII-H of pWW53 in } \\
\text { pKT230 }\end{array}$ \\
\hline & pWW53-1013 & $\begin{array}{l}14.0 \mathrm{kbp} K p n \mathrm{I}-\mathrm{C} \text { of pWW53 in } \\
\text { pKT230 }\end{array}$ \\
\hline & pWW53-1201 & $\begin{array}{l}5 \cdot 3 \mathrm{kbp} S m a \mathrm{I}-K p n \mathrm{I} \text { fragment obtained } \\
\text { by } S m \text { aI digestion of pWW53-1013 }\end{array}$ \\
\hline & pWW53-1001 & $\begin{array}{l}3.2 \mathrm{kbp} \text { BamHI fragment of } \mathrm{pWW} 53- \\
3010 \text { cloned into pFBI. } 1\left(x y l S 3_{\mathrm{pWW} 53}\right)\end{array}$ \\
\hline & pWW53-1002 & $\begin{array}{l}3.2 \mathrm{kbp} \text { Bam HI fragment of pWW53- } \\
1001 \text { cloned into pWW53-3002 }\end{array}$ \\
\hline & pWW53-1003 & $\begin{array}{l}3.2 \mathrm{kbp} \text { BamHI fragment of pWW53- } \\
1001 \text { cloned into pWW53-3004 }\end{array}$ \\
\hline \multicolumn{3}{|c|}{ Recombinant plasmids from pDK 1} \\
\hline & pDK2-3351 & $1.35 \mathrm{kbp}$ HindIII-S in pUC18 \\
\hline & pDK2-3352 & $\begin{array}{l}\text { HindIII-S in pUC18 in opposite } \\
\text { orientation to } 3351\end{array}$ \\
\hline & pDK2-3353 & $1 \cdot 1 \mathrm{kbp}$ HindIII-U in pUC18 \\
\hline & pDK2-3376 & $1.45 \mathrm{kbp} X h o \mathrm{I}-\mathrm{C}^{\prime}$ in pUC18 \\
\hline & pDK2-3377 & $\begin{array}{l}X h o I-C^{\prime} \text { in pUC18 in opposite } \\
\text { orientation to } 3376\end{array}$ \\
\hline & pDK2-3364 & 3.9 kbp BamHI-D in pUC18 \\
\hline & pDK2-3365 & $\begin{array}{l}\text { BamHI-D in pUC18 in opposite } \\
\text { orientation to } 3364\end{array}$ \\
\hline
\end{tabular}

Enzyme assays. Induction by $m$-toluate was achieved by growing $P$. putida cells in liquid minimal medium with $5 \mathrm{~mm}-m$-toluate as sole source of carbon and energy. Cells were harvested after $24 \mathrm{~h}$, cell extracts prepared and enzymes assayed as described previously (Assinder \& Williams, 1988).

DNA manipulations. Vector and recombinant plasmid DNA isolation, construction of recombinant DNA, Escherichia coli transformation, nick-translation to radiolabel DNA with ${ }^{32} \mathrm{P}$ and DNA-DNA hybridizations were by standard procedures (Sambrook et al., 1989). pWW53, pDK1 and their derivatives were extracted according to Wheatcroft \& Williams (1981).

DNA subcloning strategies and sequencing. Sequencing was performed on both DNA strands using the double-stranded dideoxy chain-termination procedure (Sanger et al., 1977) either with M13 forward and reverse primers, or with custom-synthesized oligonucleotide primers. Nested deletions of clones for sequencing were obtained using S1 nuclease and exonuclease III (Henikoff, 1984) using a Pharmacia kit.

(i) Sequencing of $x y l S 1_{\mathrm{pww}}$. The $3.9 \mathrm{kbp} \mathrm{XhoI}$ fragment of pWW53 contained in pWW53-3508 (Keil et al., 1987b) was used as a source of $x y l S 1$ for DNA sequencing. Contiguous $0.6 \mathrm{kbp} B g I I \mathrm{I}$ and $1.2 \mathrm{kbp}$ $B g I I I-S m a I$ fragments were subcloned into pUC18 in both orientations.

(ii) Sequencing of $x y l S 2_{\mathrm{pww}}$. The $14.0 \mathrm{kbp} \mathrm{KpnI} \mathrm{fragment} \mathrm{KC}$ of pWW53 was cloned into pUC19 giving pWW53-1013. Internal SmaI fragments were excised by digestion with $S m a I$ and religation to generate pWW53-1201. This carries the $x y l S 2_{\text {pww53 }}$ gene on a $5.3 \mathrm{kbp}$ SmaI-KpnI fragment.

(iii) Sequencing of $x y l S 3_{\mathrm{pww} 53}$. The $3.2 \mathrm{kbp}$ BamHI fragment carrying $x y l S 3_{\mathrm{pWw} 53}$ in $\mathrm{pWW53-1001}$ was subcloned by transferring the $2.0 \mathrm{kbp} B a m \mathrm{HI}-B g / \mathrm{II}$ fragment into the $B a m \mathrm{HI}$ site of pUC19 in both orientations.

(iv) Sequencing of $x y l S 1_{\mathrm{pDK} 1}$. Determination of the sequence of $x y l S 1$ started with $3.9 \mathrm{kbp}$ BamHI-D. This was cloned into pUC19 in both orientations to give plasmids pDK2-3364 and pDK2-3365. A small $(0.7 \mathrm{kbp})$ SmaI fragment was deleted from pDK2-3364 between the $S m a I$ site in the multicloning site of the vector and the internal SmaI site in the insert. Similarly a PstI fragment was excised from pDK23365 using the multicloning site and an internal site in the insert leaving a $2.4 \mathrm{kbp}$ PstI-BamHI insert.

(v) Sequence of $x y l S 2_{\mathrm{pDK} 1}$. The sequence of $x y l S 2$ was initiated from three fragments cloned into pUC18, the adjacent $1.35 \mathrm{kbp}$ HindIII-S (pDK2-3351 and pDK2-3352) and $1.1 \mathrm{kbp}$ HindIII-U fragments (pDK2-3353), and the overlapping $X$ hoI- $\mathrm{C}^{\prime}$ fragment (pDK2-3376 and pDK2-3377).

\section{Results}

\section{Identification of three xylS homologues on $p W W 53$}

A $300 \mathrm{bp}$ fragment internal to the $x y l S_{\mathrm{pww}}$ gene (gift of F. C. H. Franklin, University of Birmingham, UK) was radiolabelled and hybridized to pWW53 DNA cut with a range of restriction endonucleases. Two regions carrying putative $x y l S$ homologues were identiifed in addition to that already shown to exist at the end of operon 1 (to be referred to as $x y l S 1_{\mathrm{pww} 53}$ ) (Keil et al., $1987 b$; Osborne et al., 1988). One of these regions, denoted $x y l S 2_{\mathrm{pww} 53}$, was at the downstream end of 


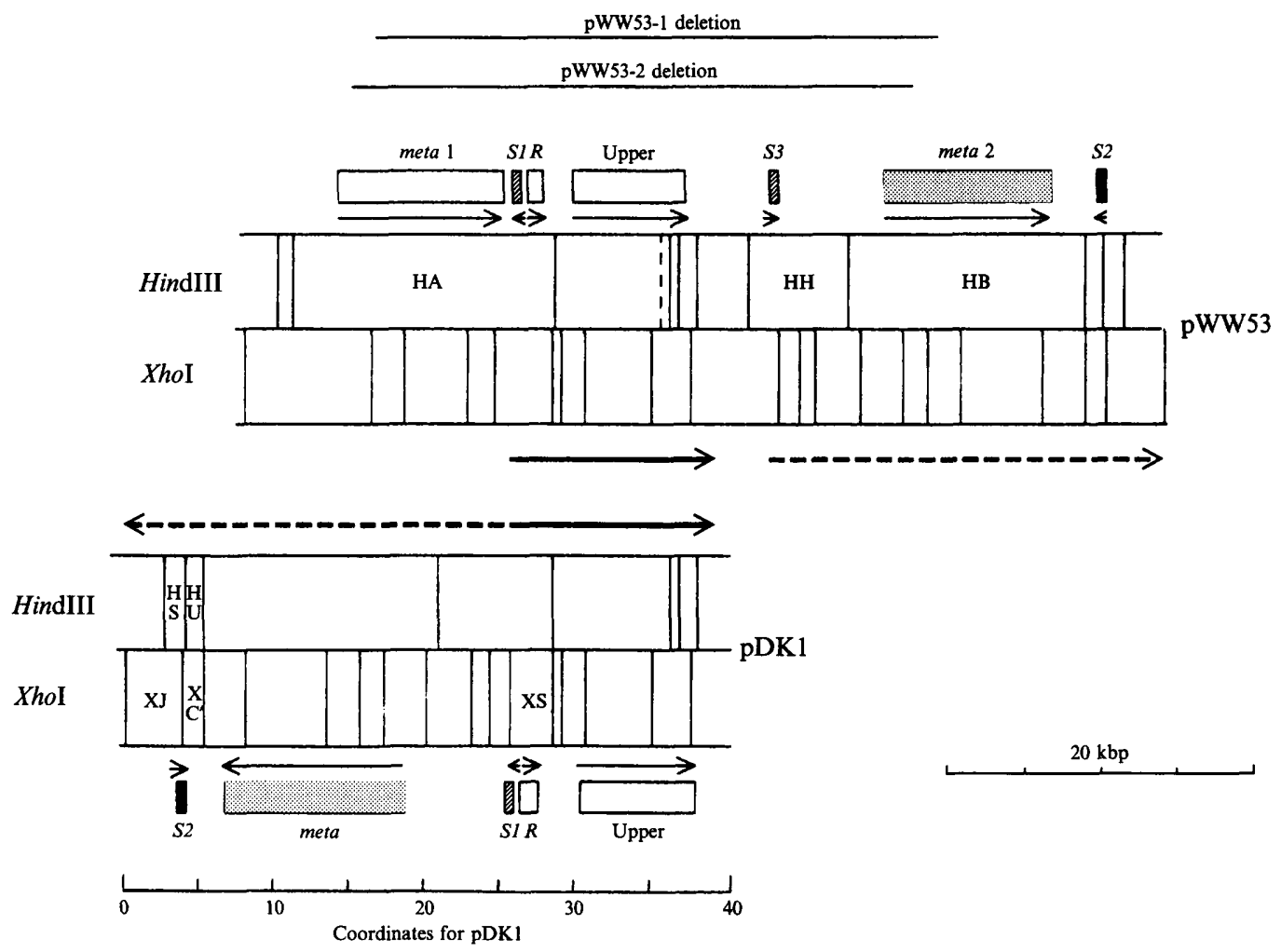

Fig. 1. Restriction maps of the areas containing the $x y l$ genes of TOL plasmids pDK1 and pWW53. The maps are aligned to highlight the structural relationships between the two plasmids. The restriction map for Xhol and HindIII for pDK1 is taken from Shaw \& Williams (1988) and represents the pDK1 insert in the RP4:pDK1 cointegrate pDK2. The restriction map for pWW53 has not been published previously in this form but some of the data is from Osborne et al. (1988). The two maps have been aligned on the two upper pathway operons ( $x y l C M A B N$; upper). The extent of homology around this region is shown by the two bold arrows. The single HindIII site in this region which is present on pWW53 but not on pDK1 is shown as a dashed line. The second region of homology extends between $x y l S 3(S 3)$ past $x y l S 2(S 2)$, including meta pathway operon 2 (meta 2 ) on pWW53 and from $x y l S I(S 1)$ and past $x y l S 2$, including the meta pathway operon 1 (meta 1 ) on pDK1 and is denoted by the bold dashed arrows: there are no differences in restriction sites for nine enzymes within this region. The three $x y l S$ homologues which are proposed as being involved in the rearrangement of catabolic DNA from a pWW53-like plasmid to give pDK1 are shown as cross hatched boxes: $x y l S 1_{\mathrm{pww} 53}$ and $x y l S 3_{\mathrm{pww} 53}$ appear to have recombined to give the hybrid $x y l S 1_{\mathrm{pDK} 1}$. The two $x y l S 2$ homologues which have been shown to have identical sequences are shown as black boxes. The two meta pathway operons which are indistinguishable by restriction mapping and presumably have very similar, if not identical sequences, are shown as shaded boxes. The directions of transcription of the various transcription units are shown as light arrows. Relevant restriction fragments mentioned in the text are lettered. The extent of the deletions in pWW53 which have occurred in the formation of the plasmids pWW53-1 and pWW53-2 are shown above the pWW53 map. R, $x y l R$.

operon 2, although not on the large fragment HindIII-B (HB) which carries the operon (Fig. 1). A third region of homology ( $\left.x y l S 3_{\mathrm{pww} s 3}\right)$ was identified between the two meta pathway operons (Fig. 1).

A $1.5 \mathrm{kbp} B g l \mathrm{II}-\mathrm{Smal}$ fragment of pWW53 HindIII-A (HA), shown by Keil et al. $(1987 b)$ to carry part of $x y l R_{\mathrm{pww} 53}$ was used as a probe against digests of DNA from pWW53, pWW53-1 and pWW53-2. It hybridized only to the region adjacent to $x y l S 1_{\mathrm{pww} s 3}$ at the downstream end of operon 1 on pWW53, implying that $x y l R$ is present in a single copy on pWW53. As confirmation of this, no hybridization was observed to the deletion derivatives of pWW53, pWW53-1 and pWW53-2, since the downstream end of operon 1 is deleted in these plasmids (Fig. 1).
Functional analysis of $x y l S 3_{\mathrm{pww} 53}$

The ability of $x y l S 3_{\mathrm{pww} 53}$ to act as a regulator of meta pathway operons was examined using the following strategy (Fig. 2). HindIII fragment $\mathrm{H}$ from pWW53 which carries $x y l S 3$ (Fig. 1) was cloned into pKT230 (pWW53-3010). Using the unique vector BamHI site, the $3.2 \mathrm{kbp}$ Bam HI fragment was subcloned into pFBI.1 giving pWW53-1001. The BamHI fragment from pWW53-1001 was cloned into pWW53-3002 (consisting of pWW53 HB cloned into the HindIII site of pKT230; Osborne et al., 1988) to give plasmid pWW53-1002. This construct allowed us to study the interaction between $x y l S 3_{\mathrm{pww} 53}$ and the promoter of meta pathway operon 2, $P m 2_{\text {pww53 }}$. It was not possible to make an exactly 


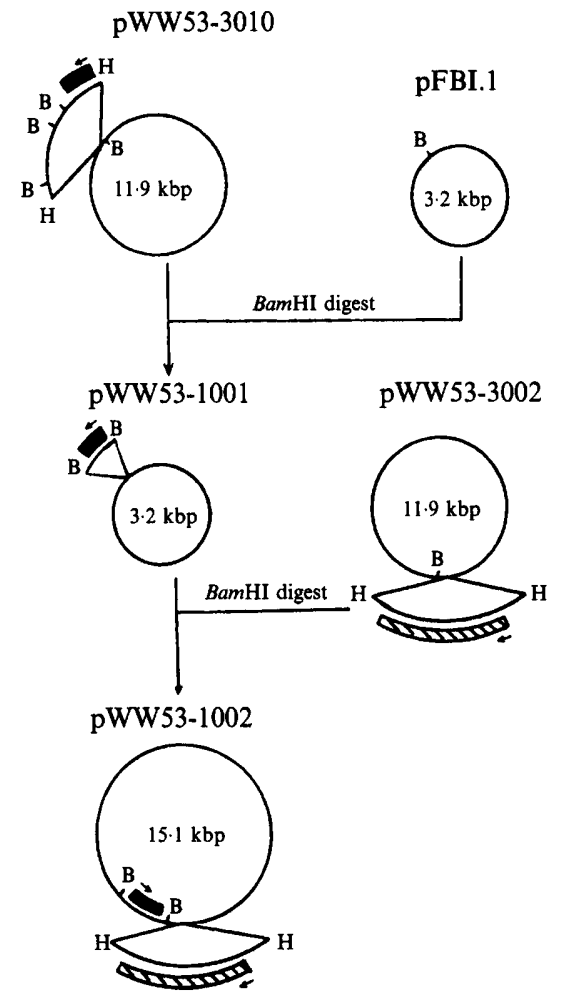

Fig. 2. Cloning strategy for the functional analysis of $x y l S 3_{\mathrm{pww} 53}$. The sizes of the vectors are indicated within the circles. The location of $x y l S 3_{\mathrm{pWw} 53}$ is shown as a black box. The location of pWW53 meta operon 2 is shown as a hatched box. H, HindIII; B, BamH1. The origins of the plasmids and accurate sizes of the cloned inserts are given in Table 1.

Table 2. Specific activities of meta pathway enzymes in PaW130 carrying the $x y l S 3_{\mathrm{pww} 53}$ gene and either the hybrid meta pathway operon from $p W W 53-2\left(H A^{\prime}\right)$ or meta operon 2 from $p W W 53(H B)$

\begin{tabular}{cccccc}
\hline \hline & & & \multicolumn{3}{c}{ Specific activity* } \\
\cline { 4 - 6 }$x y l S 3$ & $\begin{array}{c}\text { meta } \\
\text { operon }\end{array}$ & m-Toluate & C23O & HMSD & HMSH \\
\hline- & HA $^{\prime}$ & - & 13 & 5 & 2 \\
- & HA $^{\prime}$ & + & 36 & 17 & 12 \\
+ & HA' $^{\prime}$ & - & 5 & 4 & 2 \\
+ & HA $^{\prime}$ & + & 139 & 105 & 113 \\
- & HB & - & 7 & 4 & 1 \\
- & HB & + & 17 & 7 & 8 \\
+ & HB & - & 5 & 5 & 2 \\
+ & HB & + & 183 & 130 & 151 \\
\hline \hline
\end{tabular}

* Specific activities are expressed as milliunits (mg protein $)^{-1}$ and represent the mean of three replicates. $\mathrm{C} 23 \mathrm{O}$, catechol 2,3-oxygenase; HMSD, 2-hydroxymuconic semialdehyde dehydrogenase; HMSH, 2hydroxymuconic semialdehyde hydrolase.

equivalent construct for the promoter of meta pathway operon 1, $P m 1_{\mathrm{pww} 53}$, since HA contains a site for BamHI. As an alternative, the BamHI fragment from pWW531001 was cloned into pWW53-3004 (consisting of the novel HindIII fragment $\mathrm{HA}^{\prime}$ of pWW53-2 cloned into pKT230; Osborne et al., 1988) to give plasmid pWW53-1003. This novel HindIII fragment of pWW532 contains a hybrid meta operon with the upstream region of meta operon 1 fused through spontaneous recombination to the downstream region of operon 2 (see Fig. 1) (Osborne et al., 1988). This construct allowed us to study the interaction between $x y l S 3_{\mathrm{pww} 53}$ and $P m l_{\text {pww53. }}$.

Plasmids pWW53-3002, pWW53-3004, pWW53-1002 and pWW53-1003 were individually mated into the plasmid-free $P$. putida strain $\mathrm{PaW} 130$ and representative meta pathway enzymes were assayed after growth in the presence and absence of $m$-toluate as inducer (Table 2). Induction was observed only in the presence of both the $x y l S 3_{\mathrm{pww} 53}$ gene and $m$-toluate.

\section{Identification of two xylS homologues on $p D K 1$}

In our earlier paper on pDK1 (Shaw \& Williams, 1988) we demonstrated that at the upstream end of the upper pathway operon $x y l C M A B N$ of $\mathrm{pDK} 1$ there were two adjacent $B g I I$ sites as found on pWW0 in the centre of the divergently transcribed $x y l R S$ gene pair (Spooner $e t$ al., 1986). These sites were located on a $3.9 \mathrm{kbp}$ BamHI fragment D (BD) and the overlapping $2.8 \mathrm{kbp} \mathrm{XhoI}$ fragment $S$ (XS) (around coordinates 25-27, Fig. 1). Both fragments hybridized with the $x y l S_{\mathrm{pww}}$-specific probe (see above) and, when BD was inserted into a recombinant plasmid containing the cloned pDK1 meta pathway operon, the meta pathway enzymes were inducible by $m$-toluate (Shaw \& Williams, 1988). BD appears therefore to carry a functional $x y l S$ gene which we have termed $x y l S 1_{\mathrm{pDK} 1}$.

Plasmid pDKM1 is a spontaneous deletion derivative of pDK1 (Kunz \& Chapman, 1981) which carries an inducible meta pathway and supports growth on $m$ - and $p$-toluates but has lost the upper pathway operon as part of its deletion. Restriction digests showed that the fragments around the $x y l S 1_{\mathrm{pDK} 1}$ gene were not present on pDKM1 (results not shown) having been deleted with the adjacent upper pathway operon and its $x y l R$ gene (see Fig. 1). However, the $x y l S_{\mathrm{pww} 0}$-specific probe did hybridize to Southern blots of digested pDKM1 at positions corresponding to the $3.8 \mathrm{kbp} \mathrm{XhoI} \mathrm{fragment} \mathrm{J}$ (XJ) and the overlapping $1.35 \mathrm{kbp}$ HindIII-fragment $\mathrm{S}$ (HS); we have termed this region of homology $x y l S 2_{\mathrm{pDK}_{1}}$.

Sequence determination of the $p W W 53$ and $p D K 1$ xylS genes

For clarity only the DNA sequences corresponding to the ORF of $x y l S_{\mathrm{pww} 0}$ plus a short upstream region are 


$$
-24 \quad-12
$$

(a) CTTAAAAAGAACGTCTTCGTTCTGCTTGGCGTTATTTTTGCTTGGAAAAGTGGTCACTGA

(b) : : : : : : : : : : : : : :T : : : : : : : : : : : : : : :A: : : : : : : : : : : : : :C: : : : : : : : : : : : : :

(c) ccggctcggtcgcgataccgcggacatgatccagctcattaaggagttcgacgacatggg

(d) tatattattctacgcagccgatttgaccgggcactatggtgcttcgatggcgggggctgg

(e) : : : : : : : : : : : : : : : : : : : : : : : : : : : : : : : : : : : : : : : : : : : : : : : : : : : : : : : : : :A:

TTGCAAAAAGGATGGCGCAACGTGGCAATGGGGGTAACCCGTATACGCATCACGTCGAGA : : : : : : : : : : : : : : : : : : : : : : : : : : : : : : : : : : : : : : : : : : : : : : : : : : : : : : : : : : : : cgtggccatccgatttttggatgacggcatcagcacagagggaaccatgggcaaaatggt tcattggctgaccgttgatcggctcgcgtcatggcttgggcatattgcgagtatcaatgg : : : : : : : : : : : : : : C: : : : : : : : : : : : : : : : : : : : : : : : : : : : : : : : : : : : : : : : : : : : :

TGCATTTTCATCGACTTGGCGCCTTTCTACATCACACCAAGCAGCCCACATTAAAATAAG : : : : : : : : : : : : : : : C : : : : : : : : : : : :T: : : : : : : : : : : : : : : : : : : : : : : : : : : : : : : ggtgaccatcctgtcagccgtggctcaggccgaacgcctgcggatactggaacggaccaa agtgtgcgaggtgggcagcctaggccttgagttcctcgtaacccacata: AA : : T: : : : : $::::::::::::::: C::::::::::::::::::::::::::::::::::::::::::::::::$

$$
x Y I S \rightarrow-\rightarrow
$$

AGAACCGTGAACTATGGATTTTTGCTTATTGAACGAGAAAAGTCAGATCTTCGTCCACGC : : : : : : : : : :G : :ATG : : : : : :C: : : : : : : : : : : : : : : : : : : : : : : : : : : : : : : : : :T: : cgaaggtcgtttggaagcaaaggccaagggcgtgaagtttggccgcaaacctacggtgga : :C: : : : : : :GT:ATG: : : :G:C: : : :G: : : : : : : : : : : : : : :G: : : : : : : : : :A:T: : $:::::::::: G::$ ATG: : : : : : : : : : : : : : : : : : : : : : : : : : : : : : : : : : : : : : : : : : : :

CGAGCCCTATGCAGTCTCCGATTATGTTAACCAGTATGTCGGTACGCACTCTATTCGCCT : : : : : : : : : : : : : : : : : : : : :C: : : : : : : : : : : : : : : : : : : : : : : : : : : : : : : : : : : : : : caaagccgaggtattcacgctccacggtcagggtatcagtgcgatggaaattgccaaacg : : : : : : : : :CTTC: : : : : : : :C: :C: : : : : : : :AC: : : : : : : :T: : : : : :G: : : : : : : : : : : : : : : : : : : : : : : : : : : : : : : : : : : : : : : : : : : : : : : : : : : : : : : : : : : : : : : : : : : : :

GCCCAAGGGCGGGCGCCCGGCAGGCAGGCTGCACCACAGAATCTTCGGATGCCTCGACCT : : : : : : : : : : : : : : : : : : : : : : : : : : : : : : : : : : : : : : : : : : : : : : : : : : : : : : : : : : : : : : actgaagattggtcgctcgacggtctacaaagtgctggcatcataagttcatctgacaga : : : : : : :A:T: : :T: : : : : :A: :C: : :C: : :A: : : : : :C:CT:: : :CA::::T::T:: : : : : : : : : : : : : : : : : : : : : : : : : : : : : : : : : : : : : : : : : : : : : : : : : : : : : : : : : : :

GTGTCGAATCAGCTACGGCGGTAGCGTGAGGGTAATCTCGCCTGGATTAGAGACCTGTTA : : : : : : : : : : : : : : : : : : : : : : : : : : : : : : : : :G: : : : : : : : : : : : : : : : : : : : : : : : : : cgcgtgctgtcagccccgcccatgcttagcgtactttaaaatcccttttctgaggcgccc : : : : : : : : : : : : : : :T: : : : : : : : : : :A: : : : :G:C: : : : : :A: :C: :G: :A:: : : :C:: : : : : : : : : : : : : : : : : : : : : : : : : : : : : : : : : : : : : : : : : : : : : : : : : : : : : : : : : : :

TCATCTGCAAATAATACTCAAAGGCCATTGCCTGTGGCGTGGCCATGGCCAGGAGCACTA : : : : : : : : : : : : : : : : : : : : : : : : : : : : : : : : : : : : : : : : : A: : : : : : : : : : : : : : : : : :

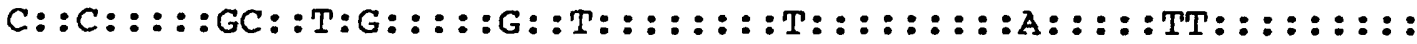

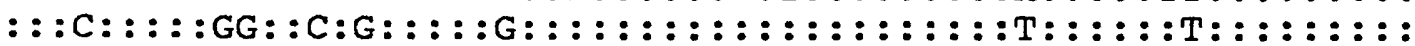
: : : : : : : : : : : : : : : : : : : : : : : : : : : : : : : : : : : : : : : : :T:: : : : : : : : : : : : : : : 
TTTTGCGCCGGGCGAACTATTGCTGCTCAATCCGGATGACCAAGCCGACCTGACCTATTC : : : : : : : : : : : : : : : : : : : : : : : : : : : : : : : : : : : : : : : : : : : : : : : : : : : : : : : : : : : : : : : : : : : :A: : : : : : : : : : :G: :A::::C: : : : : : : : :GC::G: :G: : : : :T: :::: : : : : :T : : : : : : :T: : : : : : : : : : : :A : : : : : : : : : : : : : : :G: : :G: : : : : : : :T: : : : : : : : :T: : : : : : : : : : : : : : : : : : : : : : : : : : : : : : : : : : : : : : : : : : : : : : : : : : :

AGAAGATTGCGAGAAATTTATCGTTAAATTGCCCTCAGTGGTCCTTGATCGGGCATGCAG 600 : : : : : : : : : : : : : : : : : : : : : : : : : : : : : : : : : : : : : : : : : : : : : : : : : : : : : : : : : : : : : :

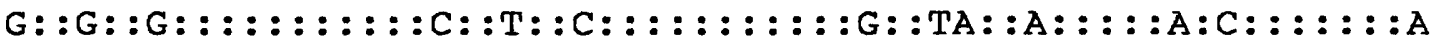
G: :G: : : : :T: : : : : : : : C: : : : :C: : : : :A:: : : : : : : : : : : : :C: : : : : : : : : : : : : : : : : : : : : : : : : : : : : : : : : : : : : : : : : : : : : : : : : : : : : : : : : : : : : : : : : : : : : : : :

TGACAACAATTGGCACAAGCCGAGGGAGGGTATCCGTTTCGCCGCGCGACACAATCTCCA 660 : : :G: : : : : : : : : : : : : : : : : : : : : : : : : : : : : : : : : : : : : : : : : : : : : : : : : : : : : : : : : : :GCT: : : : : : : : :G: : : : : : : :T:GA: : : : : : : : : : : :C: :C:C: : : : :T:GC: :G: : $:::$ : :G:T : : : : : : : : : : : : : : : :T: : : : : : : : : : :C: : :A: :A: : : : : : : : : :C::G: : : : : : : : : : : : : : : : : : : : : : : : : : : : : : : : : : : : : : : : : : : : : : : : : : : : : : : : :

GCAACTCGATGGCTTTATCAATCTACTCGGGTTAGTTTGTGACGAAGCGGAACATACAAA

720 : : : : : : : : : : : : : : : : : : : : : : : : : : : : : : : : : : : : : : : : : : : : : : : : : : : : : : : : : : : $::: G::$ TA: : : : : : :C: : : : : : : : :A: : : :AC:G: : : : : : : : : : : : : : : : : : : : : :ACAT : : : : : : : : : : : : : : : : : : : : : : :G: :T:: :C:G: : : : : : : : : : : : : : : : :G: : : : : : : : : : : : : : : : : : : : : : : : : : : : : : : : : : : : : : : : : : : : : : : : : : : : : : : : : : : : : : : : :

GTCGATGCCTCGGGTCCAAGAGCACTATGCGGGGATCATCGCTTCCAAGCTGCTCGAAAT : : : : : : : : : : : : : : : : : : : : : : : : : : : : : : : : : : : : : : : : : : : : : : : : : : : : : : : : : : : : G: : : : : :A:CTT : : :GGCG : : : : : : : :CA : :AA: : : : : : : : : :A: : : : : : : : : : : : :G:C T: : : : : : : : : : : : : : : : :G: :AT: : : : :A:: : : : : : : : :T:: :A: : : : : : : : : : : : :G: : : : : : : : : : : : : : : : : : : : : : : : : : : : : : : : : : : : : : : : : : : : : : : : : : : : : : : : : : : :

GCTGGGCAGCAATGTCAGCCGTGAAATTTTCAGCAAAGGTAACCCGTCTTTCGAGCGAGT : : : : : : : : : : : : : : : : : : : : : C: : : : : : : : : : : : : : : : : : : : : : : : : : : : : : : : : : : : : : : : :CA : : : : : : : : : : : : : : : :CA : :GGC: : :GT:G : : : :C: : : : :A:G : : : : : : : : : : : :

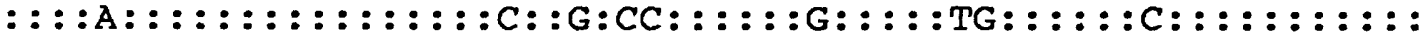
: : : : : : : : : : : : : : : : : : : : : : : : : : : : : : : : : : : : : : : : : : : : : : : : : : : : : : : : : :

CGTTCAATTCATTGAGGAGAATCTCAAACGGAATATCAGCCTTGAGCGGTTAGCGGAGCT : : : : : : : : : : : : : : : : : : : : : : : : : : : : : : : : : : : : : : : : : : : : : : : : : : : : : : : : : : : : : : : : : :G: : : : : : : : : : :A: : :G: : : : : : : : :G: : : : : : : : : : : : : :A: : : : : : : : : : : : : : : : : :G: : : : : : : : : : :C: : : : : : : : : :A::GC: : : : : : : : : : : : : :AC:G: : : : : : : : : : : : : : : : : : : : : : : : : : : : : : : : : : : : : : : : : : : : : : : : : : : : : : : : : : : : : : : : : : :

GGCGATGATGAGTCCACGCTCGCTCTACAATTTGTTCGAGAAGCATGCCGGCACCACGCC : : : : : : : : : : : : : : : : : : : : : : : : : : : : : : : : : : : : : : : : : : : : : : : : : : : : : : : : : : : : : : : :C: : : : : : :C: : : : : : : :C: : : : : : :CCA: : : : : : : : : : : : : : A : : : : : : : : : : : : : : : : :C: : : : : : :C: : : : : : : : : : : : : : : :C: : : : : : : : : : : : : : : : : :T: : : : : : : : : : : : : : :C: : : : : : :C: : : : : : : : : : : : : : : :C: : : : : : : : : : : : : : : : : :T: : : : : : : : : : : 
GAAGAACTACATCCGCAACCGCAAGCTCGAAAGCATCCGCGCCTGCTTGAACGATCCCAG

\section{CAAAAAGGAAGTGGCTTGA}

\section{$::::::::::::::::: T G A$ \\ $:::{ }^{\prime} \mathrm{G}: \mathrm{T}::::::$ :CA:C: :TTCAAGGGAGTCTAGCCTGTCCTCGCTCTTTTGA \\ $:::::{ }^{\wedge} T::::::::::::$ TCCCGAGGAGAGCCTGCCCCCACTCCCTTGA \\ $::::{ }^{\wedge} \mathrm{T}:::::::::::$ :TCCCGAGGAGAGCCTGCCCCCACTCCCTTGA}

Fig. 3. Comparison of the nucleotide sequence of $(a)$ the known ORF of $x y l S_{\mathrm{pww} 0}$ with the aligned sequences of regions spanning $(b)$ $x y l S 1_{\mathrm{pWw} 53},(c) x y l S 2_{\mathrm{pWw} 53}$ and $x y l S 2_{\mathrm{pDK} 1}$ (both identical), $(d) x y l S 3_{\mathrm{pWw} 53}$ and $(e) x y l S 1_{\mathrm{pDK1}}$. The sequences were optimally aligned using DNASIS (Pharmacia). Colons indicate identity with the pWW0 sequence. Extended regions of non-homology with pWW0 are given in lower case. Gaps introduced into the sequences to achieve optimal alignment are indicated by ^. The positions of the $-12,-24$ promoter for $x y l S_{\mathrm{pww} 0}$ (Inouye $e t$ al., 1986) are underlined. The sequences of $(b)$ and $(e)$ are virtually identical to $(a)$ in the region upstream of the ORF, whereas those of $(c)$ and $(d)$ are non-homologous. A region showing homology to the $-12,-24$ promoter consensus in $(d)$ is underlined (bases 29-42) although its functional significance has not been established. The transcriptional start for $x y l S_{\text {pwwo }}$ is indicated by a horizontal arrow (Ramos et al., 1987). The proposed ORFs are as follows (putative start and stop codons are italicized): (a) 194-1159 (Inouye et al., 1986), (b) 194-1159, (c) 719-1192, (d) 194-1189 and (e) 194-1189. An in-frame stop codon (334-346) in the region of $(c)$ which is non-homologous to $(a)$ is underlined.

presented (Fig. 3) together with the deduced amino acid sequences of the proteins (Fig. 4).

A total of $1603 \mathrm{bp}$ around $x y l S 1_{\mathrm{pww} 53}$ has been sequenced, starting at the $B g l I I$ site within $x y l R_{\mathrm{pww}}$ and extending 86 bp beyond the end of the XylS encoding region. The putative ORF gives a protein of 321 amino acids with an $M_{\mathrm{r}}$ of 36580 . For $x y l S 2_{\mathrm{pww} 53}, 1447 \mathrm{bp}$ were sequenced, similarly commencing at a $B g h I$ site upstream of the gene. Optimum alignment with $x y l S_{\mathrm{pww}}$ shows homology only with the $3^{\prime}$ end of the gene within which region there is only one potential XylS-like ORF (Fig. 3) of 157 amino acids $\left(M_{\mathrm{r}}=17894\right)$. A sequence of $1346 \mathrm{bp}$ surrounding $x y l S 3_{\mathrm{pww} 33}$ was determined in which there is a single ORF of 331 amino acids $\left(M_{\mathrm{r}}=37845\right)$.

In the case of $x y l S I_{\mathrm{pDK} 1}, 1679 \mathrm{bp}$ were sequenced, with a putative ORF of 331 amino acids $\left(M_{\mathrm{r}}=37924\right)$. The sequence of $x y l S 2_{\mathrm{pDK} 1}$ was identical to that of $x y l S 2_{\mathrm{pww} 53}$ and therefore encodes a possible truncated XylS-like protein of 157 amino acids $\left(M_{\mathrm{r}}=17894\right)$.

\section{Discussion}

\section{Regulation of meta pathway operons on pWW53}

The arrangement of catabolic genes on TOL plasmid pWW53 is clearly more complex than that on pWW0 (Franklin et al., 1981). In addition to the large duplication of the meta pathway operon identified previously (Osborne et al., 1988), there exist three homologues of $x y l S$. Two of these ( $x y l S 1$ and $x y l S 3)$ have definitively been shown to encode positive regulator proteins for the meta pathway genes. The expression of the meta pathway enzymes must involve interactions between these regulatory proteins and the operatorpromoter regions of the two meta pathway operons. Although both meta pathway operons are functional, there are major differences in the specific activities of their encoded enzymes: the specific activities encoded by operon 1 are approximately 10 -fold higher than those on operon 2, even when both operons are cloned on 


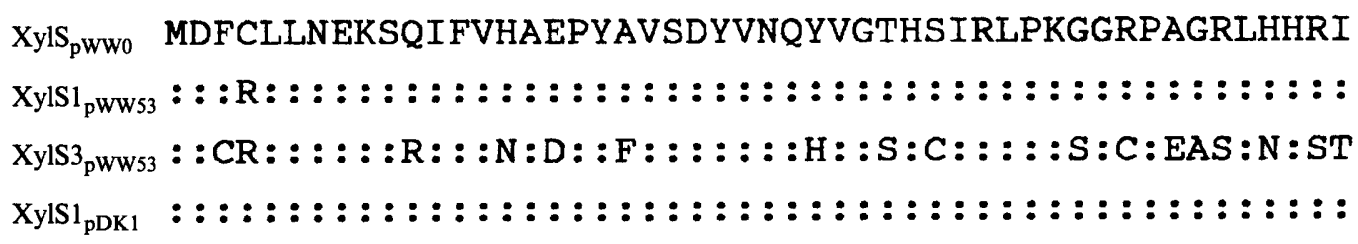
FGCLDLCRISYGGSVRVISPGLETCYHLQI ILKGHCLWRGHGQEHYFAPG : :G: : : : : : : : : : : : : : : : : : : : : : : : : : : : : : : : : : : :D: : : : : : : : : : : :S: : : : : : : : : : : : : :T: : : : : : : : : : :VL: : : : : : : : :Y:L: : : :S: : : : : : : : : : : : : : : : : : : : : : : : : : : : : : : : : : : : : : : : : :Y: : : : : :S: : ELLLLNPDDQADLTYSEDCEKF IVKLPSVVLDRACSDNNWHKPREGIRFA : : : : : : : : : : : : : : : : : : : : : : : : : : : : : : : : : : : : E: : : : : : : : : : : : : : : : :I:: : :R: : : : : : : : : : : : : : : : : : : : : : : : :ESY: : : :S: : : : :T : : : : : : : : : : : : : : : : : : : : : : : : : : : : : : : : : : : : : : : : : : : : : : : : : : ARHNLQQLDGF INLLGLVCDEAEHTKSMPRVQEHYAGIIASKLLEMLGSN

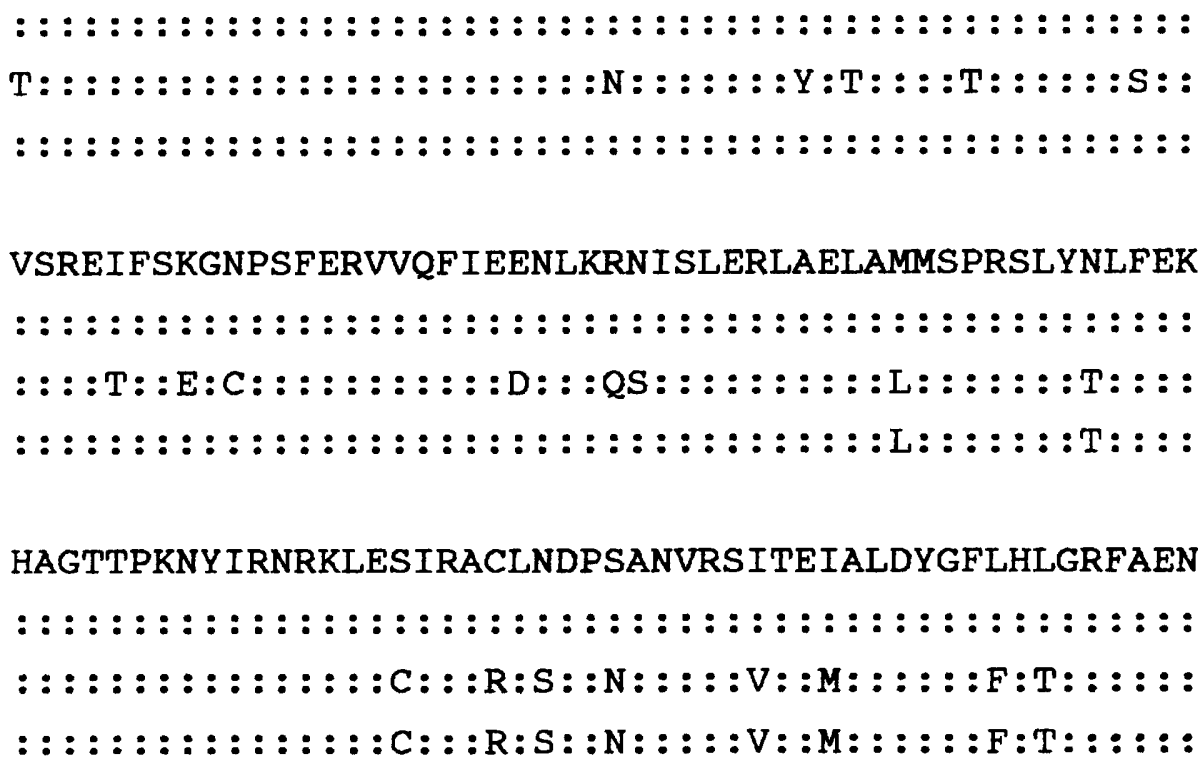

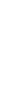


DNA sequencing of the two operon promoters, $P m l_{\mathrm{pww}}$ and $P m 2_{\mathrm{pww} 3}$, as part of this study (data not shown) supports this view by demonstrating that both promoters are very similar and both highly homologous to $P m_{\mathrm{pww}}$.

\section{Functional analysis of the $p W W 53$ and $p D K 1$ xylS genes}

The regulatory function of $x y l S l_{\mathrm{pww} 53}$ has been demonstrated previously by the inducibility of the meta pathway enzymes in a $P$. putida strain carrying HA cloned into pKT230 upon which it is the only homologue (Keil et al., $1985 a$ ). The activity of $x y l S 3_{\text {pwws3 }}$ was demonstrated in this study by the inducibility of meta pathway enzymes in strains carrying this gene in conjunction with either $\mathrm{HB}$ of pWW53 or the novel HindIII fragment $\mathrm{HA}^{\prime}$ from pWW53-2 (Table 2). The data are consistent with $x y l S 3_{\mathrm{pww} 53}$ encoding a functional gene product which can interact with the promoters of both meta pathway operons.

The regulatory function of $x y l S 1_{\mathrm{pDK} 1}$ has been demonstrated in an earlier study (Shaw \& Williams, 1988).

It is impossible to state with any certainty whether the $x y l S 2$ genes from either plasmid can act as functional activators. In both cases there is very indirect evidence which points to possible functionality. This comes from deleted plasmids generated in vivo in which the $x y l S 2$ genes are the only homologues present. In the case of plasmid pWW53 the deleted derivatives are pWW53-1 and pWW53-2 (see Fig. 1; Osborne et al., 1988), and for pDK1 the deletion is in plasmid pDKM1 (Kunz \& Chapman, 1981). In $P$. putida strains carrying these plasmids the meta pathway genes are induced by benzoate or toluates (Osborne et al., 1988; Kunz \& Chapman, 1981). However, we have as yet been unable to demonstrate that either of the cloned $x y l S 2$ genes can function as benzoate- or toluate-stimulated activators in an expression system. Furthermore, a recent paper has demonstrated that a gene in the $P$. putida chromosome, which is probably ben $R$, can substitute for $x y l S$ in such an expression system although only with unsubstituted benzoate as inducer (Jeffrey et al., 1992). It is possible that the inducibility of the meta pathway genes on pWW53-1, pWW53-2 and pDKM1 could be due to this chromosomal regulator gene.

\section{Sequence analysis of the $p W W 53$ and $p D K 1$ xylS genes}

There is striking homology between $x y l S l_{\mathrm{pww} 53}$ and $x y l S_{\mathrm{pww} 0}$ at both the DNA (99\%) (Fig. 3) and amino acid $(99 \%)$ sequence level (Fig. 4$)$.

For $x y l S 3_{\mathrm{pww} 53}$, there is a high level of DNA (87\%) and amino acid (83\%) sequence homology with $x y l S_{\mathrm{pww} 0}$ within the coding portion of the gene, but there is significant divergence in the $5^{\prime}$ leader sequence (Fig. 3) and downstream of the ORF (data not shown). The upstream breakpoint in homology starts only about 23 bases upstream of the presumed translational start codon. There is a frame-shift mutation towards the end of the coding region (base 1146) which causes the C terminus of the $\mathrm{XylS} 3_{\mathrm{pww} 3}$ protein to be elongated by an additional 10 amino acid residues relative to $\mathrm{XylS}_{\mathrm{pww}}$. The deduced amino acid sequence of $\mathrm{XylS} 1_{\mathrm{pDK} 1}$ is the same length (331 amino acids) as $\mathrm{XylS}_{\mathrm{pww} 33}$ and has the same C-terminal extension.

The DNA upstream of $x y l S 1_{\mathrm{pww} 53}$ and $x y l S 1_{\mathrm{pDK} 1}$ is highly homologous to that of $x y l S_{\mathrm{pww} 0}$ to the extent that it is possible to identify the $-12,-24$ promoter (Fig. 3) and a number of the other regulatory elements which have been demonstrated or proposed for $x y l S_{\mathrm{pww}}$ (data not shown). Within the non-homologous upstream region of $x y l S 3_{\mathrm{pww} 53}$, there is a sequence showing homology to the $-12,-24$ promoter of $x y l S_{\mathrm{pww} 0}$ (Fig. 3) but no evidence has been obtained as yet to demonstrate its functional significance.

The two $x y l S 2$ sequences are identical and both present the same problem of interpretation. There is $82 \%$ identity between the $x y l S 2$ region and the pWW0 ORF downstream of base 420 but no homology upstream (Fig. 3). The possibility that $x y l S 2$ encodes a single XylS protein with a divergent $\mathrm{N}$ terminus is ruled out by the presence of an in-frame TAA stop codon (bases 344-346) (Fig. 3). In the region that is homologous to $x y l S_{\mathrm{pww}}$, there is an ORF which runs from bases 719 to 1192 with a potential ribosome-binding site (RBS) centred $10 \mathrm{bp}$ upstream of the ATG which shows good homology with other Pseudomonas RBS sequences (Spooner et al., 1986). This ORF would give rise to a protein of 157 amino acids homologous to the C-terminal portion of $\mathrm{XylS}_{\mathrm{pww} 0}$ but lacking its $\mathrm{N}$-terminal half. However, if this does encode a truncated version of $X y l S$, it is surprising that there is still such marked homology with the $x y l S_{\text {pww } 0}$ sequence upstream of its start codon. It might be expected that any similarity in DNA sequence would have been lost outside of the shortened coding region, unless the divergence of $x y l S 2$ from $x y l S_{\mathrm{pww}}$ was very recent in evolutionary terms. Analysis of both $x y l S 2$ sequences upstream of their regions of homology to the pWW0 $x y l S$ ORF has shown the presence in each case of a complete ORF with a high degree of homology to a number of recombinase and transposon resolvase genes (Assinder et al., 1992). At present the most probable explanation is that the two $x y l S 2$ homologues represent the residues of complete $x y l S$ genes into which a transposon or insertion sequence has been inserted recently. 
The presence of $x y l R$ genes on $p D K 1$ and $p W W 53$

Hybridization results have suggested that both plasmids (Keil et al., 1987b; Shaw \& Williams, 1988) contain only one region that is homologous to $x y l R_{\mathrm{pww}}$. In both plasmids this region is adjacent to their $x y l S 1$ genes. This is confirmed by the sequences upstream of both $x y l S 1_{\mathrm{pww} 53}$ and $x y l S 1_{\mathrm{pDK} 1}$ (data not shown). In both there is the start of an ORF which is highly homologous to the start of $x y l R_{\mathrm{pww} 0}$ and similarly reads in the opposite direction. No such homology is found upstream of the other $x y l S$ homologues.

\section{The relationship between $p D K 1$ and $p W W 53$}

The major point of interest concerning the two $x y l S$ homologues on pDK1 comes when we compare them with the three homologues from pWW53, taking into account the genetic organization and restriction maps of the two plasmids (Fig. 1). The plasmids share two large areas which have identical or virtually identical restriction maps. The meta pathway operon ( $x y l X Y Z L T E G F J Q K I H)$ of $\mathrm{pDK} 1 \mathrm{has}$ been cloned on a HindIII fragment (HA, Fig. 1) measured at $15.5 \mathrm{kbp}$ (Shaw \& Williams, 1988). One of the two meta pathway operons on pWW53, referred to as meta pathway operon 2 , is found on HindIII fragment $\mathrm{HB}$, measured at $15.6 \mathrm{kbp}$ (Osborne et al., 1988). The two fragments have in common 48 restriction sites for eight different enzymes. Furthermore, the identity of the two restriction maps extends about $6 \mathrm{kbp}$ upstream of the fragment carrying the operon and about $5 \mathrm{kbp}$ downstream, taking in a further 25 restriction sites (Fig. 1). Within a total length of about $26 \mathrm{kbp}$ we have found no difference in the restriction fragmentation of the two plasmids. This paper has shown the identity at the nucleotide level for the $x y l S 2$ regions which are internal to these long indistinguishable regions on the two plasmids (Fig. 3).

The second region of homology shared by pWW53 and pDK1 covers the $7 \mathrm{kbp}$ of their two upper pathway operons $(x y l C M A B N)$ together with about $2 \mathrm{kbp}$ downstream and $4 \mathrm{kbp}$ upstream, which includes the $x y l R$ genes on each plasmid. Within these regions they share 33 common sites for nine restriction enzymes. In this case, however, there is a single difference as pWW53 has one additional HindIII site towards the end of the operon (Fig. 1) which is not present on pDK1. It could be that this homology extends further downstream of the operons but we have not mapped pDK1 any further in that direction.

The two homologous regions shared by pDK1 and pWW53 differ in their relative orientations on the two plasmids and on pDK1 they are contiguous whereas on pWW53 they are separated (Fig. 1). This can be explained when the sequence of $x y l S I_{\mathrm{pDK} 1}$ (Fig. 3) is examined. The

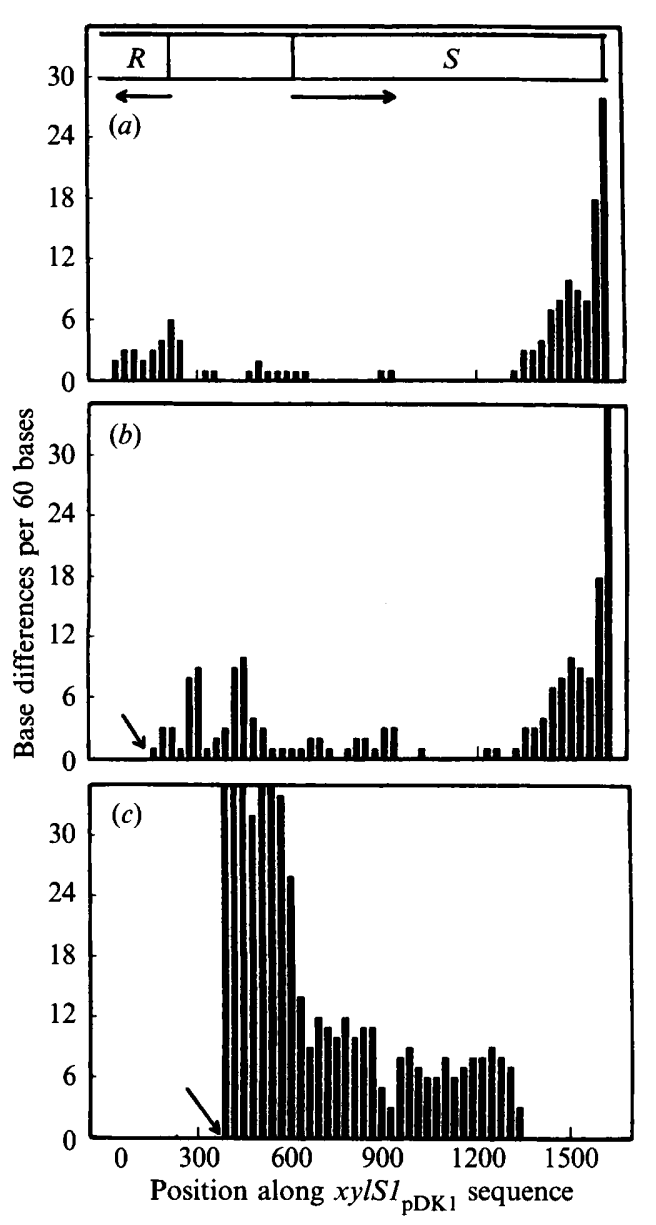

Fig. 5. Comparison of the nucleotide sequence of $x y l S 1_{\mathrm{pDK} I}$ and the flanking DNA with the homologous DNA of (a) $x y l S_{\mathrm{pww} 0},(b)$ $x y l S l_{\mathrm{pww} 53}$ and $(c) x y l S 3_{\mathrm{pww} 53}$. The sequences were optimally aligned using DNASIS (Pharmacia). The number of mismatches between the two sequences was determined within a $60 \mathrm{bp}$ window of the $x y l S l_{\mathrm{pDK} 1}$ sequence. Successive bar lines represent the windows displaced along the sequence by $30 \mathrm{bp}$ and the bar is drawn at a position on the corresponding to the mid-point of the $60 \mathrm{bp}$ window. The numbering on the $\mathrm{x}$-axis corresponds to the numbering of the bases in the Genbank file for $x y l S 1_{\mathrm{pDK} 1}$, which extends 440 bases upstream of the beginning of the sequence as presented in Fig. $3(d)$ and 633 bases upstream of its ORF. All three comparisons extend to base 1650, $24 \mathrm{bp}$ after the end of the ORF. The arrows represent the point at which it was possible to start the comparison because of the length of the sequence information available on the other strands: $(b)$ starts at base 121 , and $(c)$ at base 361 . The locations of $x y l R_{\mathrm{pww}}(R)$ and $x y l S_{\mathrm{pww} 0}(S)$ and their intergenic region is shown at the top of $(a)$, and the direction of transcription is indicated by the horizontal arrows. The compared sequence for $(a)$ is taken from Spooner et al. (1986).

gene is located at the boundary of the two regions of homology which pDK1 shares with pWW53 (Fig. 1). Comparison of its nucleotide sequence with those of $x y l S 1_{\mathrm{pww} 53}$ and $x y l S 3_{\mathrm{pww} 53}$ reveals that it appears to be a hybrid of the two (Fig. 5). From the first common nucleotide sequenced up to approximately base 1340 (as numbered on Fig. 5) the sequences of $x y l S 1_{\mathrm{pDK} 1}$ and $x y l S 1_{\mathrm{pww} 53}$ are highly homologous. Within the coding 
region there is an even distribution of base differences of around $0-3$ bases per 60 nucleotides. In the intergenic region between $x y l R$ and $x y l S$ there is a higher level of difference which is due almost entirely to two separate insertions of $8 \mathrm{bp}$ which are found only in the $x y l R S 1_{\mathrm{pww} 53}$ sequence. In fact the sequence of $\mathrm{pDK} 1$ DNA in this region and for most of the coding region of $x y l S 1$ is even closer to that of $x y l S_{\text {pwwo }}$ DNA (Fig. $5 a$ ) than that of $x y l S 1_{\text {pwws3 }}$ (Fig. $5 b$ ).

Over the same region (up to about base 1340) there is a much-lower degree of homology between the $x y l S l_{\mathrm{pDK} 1}$ DNA and the DNA around $x y l S 3_{\text {pwws3 }}$ (Fig. 5c). Upstream of the XylS ORFs there is no significant homology with base differences of around 35 per 60 bases: this agrees with the apparent absence of a $x y l R$ gene upstream of $x y l S 3_{\mathrm{pww} 33}$. Within the ORFs there are approximately 5-10 differences per 60 bases, showing a substantially lower degree of homology than found when the comparison is with the coding sequences of $x y l S 1_{\mathrm{pWw} 53}$ and $x y l S 1_{\mathrm{pDK} 1}$ (Fig. $5 b$ ). The $5^{\prime}$ end of the $x y l S 1_{\mathrm{pDK} 1}$ ORF is therefore very similar to both $x y l S_{\mathrm{pww}}$ and $x y l S l_{\mathrm{pww} 53}$ (but marginally closer to the former) and is significantly different to $x y l S 3_{\mathrm{pww} 53}$. However, from about base 1340 the level of homology with both $x y l S 1_{\mathrm{pww} 53}$ and $x y l S_{\mathrm{pww} 0}$ drops (Fig. $5 a, b$ ) to less than $90 \%$ until at the end of the ORF and into the short stretch of the downstream regions which have been sequenced it becomes insignificant. Over this same region, $x y l S 3_{\mathrm{pww} 53}$ and $x y l S 1_{\mathrm{pDK} 1}$ are identical (Fig. $5 c$ ). The hybrid nature of the $x y l S 1_{\mathrm{pDK}}$ gene $\left(x y l S 1_{\mathrm{pww} 53}: x y l S 3_{\mathrm{pww} 53}\right)$ exactly parallels its location relative to the two large regions of homology which are shared by pDK 1 and pWW53. Whereas the $5^{\prime}$ end of the gene is adjacent to a $x y l R$ gene and is upstream of the upper pathway operon, in exactly the same way as $x y l S 1_{\mathrm{pww} 53}$, its $3^{\prime}$ end is located identically to $x y l S 3_{\mathrm{pww} 53}$, both genes being upstream of regions carrying indistinguishable meta pathway operons.

Both the hybrid nature of $x y l S l_{\mathrm{pDK} 1}$ and its location can be explained if $\mathrm{pDK} 1$ is derived from a plasmid similar to pWW53. A single reciprocal recombination event between two copies of $x y l S$ on pWW53 (in this case $x y l S 1$ and $x y l S 3$ ) in the vicinity of base 900 (Fig. 3) (or codon 232, Fig. 4) would produce a gene with the structure of $x y l S 1_{\mathrm{pDK} 1}$ and would also cause a substitution of a meta pathway operon like ( $x y l X Y Z L T E G F J Q K I H)_{2}$ in place of and in the opposite orientation to (xylXYZLTEGFJQKIH), giving exactly the gene arrangement found on pDK1 (Fig. 1).

Two possible events could lead to the structure of pDK1. The recombination could occur either within a plasmid like pWW53 or between two TOL plasmids coexisting within the same strain. In either case, one ancestor of $\mathrm{pDK} 1$ would require more than one copy of a $x y l S$ gene to give the structure found. It had occurred to us that such a recombination event might have taken place in our laboratory since both strains were being studied on adjacent benches: this would make a weaker case for the occurrence of such an event being relevant to evolution in the wild. However, one argument can be brought to bear against the formation of $\mathrm{pDK} 1$ being artefactual. The $5^{\prime}$ end of $x y l S 1_{\mathrm{pDK} 1}$ is unique and is not identical to the $5^{\prime}$ ends of either $x y l S 1_{\mathrm{pww} 53}$ or $x y l S_{\mathrm{pww} 0}$ (Figs 4 and 5 ). Furthermore, the entire sequence of the meta pathway operon and the $x y l R S 1$ region of $\mathrm{pDK} 1$ has been independently determined and the two sequences are identical (R. C. Benjamin, personal communication).

Duplications appear to be a common feature of the catabolic genes of TOL plasmids and possible reasons that they might confer a selective advantage on a plasmid have been discussed elsewhere (O'Donnell \& Williams, 1991). Whether or not there is any selective advantage, the results in this paper illustrate that a consequence of the presence of such duplications is that they can serve as points at which recombination can occur to give rise to both new hybrid alleles of the genes and major rearrangements of DNA.

Some of this work was carried out with funding from the Science and Engineering Research Council. M.K.W. acknowledges receipt of a Sir William Roberts Scholarship from the University College of North Wales. C.L.P. was in receipt of sabbatical leave from the National University of Singapore.

\section{References}

Assinder, S. J. \& Williams, P. A. (1988). Comparison of the meta pathway operons on NAH plasmid pWW60-22 and TOL plasmid pWW53-4 and its evolutionary significance. Journal of General Microbiology 134, 2769-2778.

Assinder, S. J. \& Williams, P. A. (1990). The TOL plasmids: determinants of the catabolism of toluene and the xylenes. Advances in Microbial Physiology 31, 1-69.

Assinder, S. J., De Marco, P., Sayers, J. R., Shaw, L. E., Winson, M. K. \& Williams, P. A. (1992). Identical resolvases are encoded by Pseudomonas plasmids pWW53 and pDK1. Nucleic Acid Research 20, 5476.

Bagdasarian, M., Lurz, R., Rückert, B., Franklin, F. C. H., Bagdasarian, M. M., Frey, J. \& Timmis, K. N. (1981). Specific purpose plasmid cloning vectors. II. Broad host range, high copy number RSF1010-derived vectors and a host:vector system. Gene 16, 237-247.

Chatfield, L. K. \& Williams, P. A. (1986). Naturally-occurring TOL plasmids isolated from soil carry either two homologous or two nonhomologous catechol 2,3-oxygenase genes. Journal of Bacteriology 168, 878-885.

Franklin, F. C. H., Bagdasarian, M., Bagdasarian, M. M. \& TIMmis, K. N. (1981). Molecular and functional analysis of the TOL plasmid pWW0 from Pseudomonas putida and the cloning of genes for the entire regulated aromatic ring meta cleavage pathway. Proceedings of the National Academy of the Sciences of the United States of America 78, 7458-7462.

HaRAyAma, S. \& REKIK, M. (1990). The meta cleavage operon of TOL degradative plasmid pWW0 comprises 13 genes. Molecular and General Genetics 222, 113-120.

Harayama, S., RekiK, M., Wubbolts, M., Rose, K., LePpik, R. A. \& TIMMIS, K. N. (1989). Characterization of five genes in the upper 
pathway operon of TOL plasmid pWW0 from Pseudomonas putida and identification of the gene products. Journal of Bacteriology 171, 5048-5055.

HENIKOFF, S. (1984). Unidirectional digestion with exonuclease III creates targeted breakpoints for DNA sequencing. Gene 28, 351-359.

INouYe, S., Nakazawa, A. \& NaKazawa, T. (1986). Nucleotide sequence of the regulatory gene $x y l S$ on the Pseudomonas putida TOL plasmid and identification of the protein product. Gene 44, 235-242.

Jeffrey, W. H., Cuskey, S. M., Chapman, P. J., Resnick, S. \& Olsen, R. H. (1992). Characterization of Pseudomonas putida mutants unable to catabolize benzoate: cloning and characterization of Pseudomonas genes involved in benzoate catabolism and isolation of a chromosomal DNA fragment able to substitute for $x y l S$ in activation of the TOL-lower pathway promoter. Journal of Bacteriology 174, 4986-4996.

Keil, H., Keil, S., Pickup, R. W. \& Williams, P. A. (1985a). Evolutionary conservation of genes coding for meta pathway enzymes within TOL plasmids pWW0 and pWW53. Journal of Bacteriology 164, 887-895.

Keil, H., Lebens, M. R. \& Williams, P. A. (1985b). TOL plasmid pWW15 contains two non-homologous, independently-regulated catechol 2,3-oxygenase genes. Journal of Bacteriology 163, 248-255.

Keil, H., SaInT, C. M. \& Williams, P. A. (1987a). Gene organization of the first catabolic operon of TOL plasmid $\mathrm{pWW} 53$ : production of indigo by the $x y l A$ gene. Journal of Bacteriology 169, 764-770.

Keil, H., KeIL, S. \& Williams, P. A. (1987b). Molecular analysis of regulatory and structural $x y l$ genes of the TOL plasmid pWW53-4. Journal of General Microbiology 133, 1149-1158.

Kunz, D. A. \& Chapman, P. J. (1981). Isolation and characterization of spontaneously occurring TOL plasmid mutants of Pseudomonas putida HS1. Journal of Bacteriology 146, 952-964.

O'Donnell, K. J. \& Williams, P. A. (1991). Duplication of both $x y l$ catabolic operons on TOL plasmid pWW15. Journal of General Microbiology 137, 2831-2838.
Osborne, D. J., Pickup, R. W. \& Williams, P. A. (1988). The presence of two homologous meta pathway operons on TOL plasmid pWW53. Journal of General Microbiology 134, 2965-2975.

PrentKI, P. \& KIRSCH, A. M. (1982). A modified pBR322 vector with improved properties for the cloning, recovery and sequencing of blunt-ended DNA fragments. Gene 17, 189-196.

Ramos, J. L., Mermod, N. \& Timmis, K. N. (1987). Regulatory circuits controlling transcription of TOL plasmid operon encoding metacleavage pathway for degradation of alkylbenzoates by Pseudomonas. Molecular Microbiology 1, 293-300.

SambrooK, J., Fritsch, E. F. \& Maniatis, T. (1989). Molecular Cloning: A Laboratory Manual, 2nd edn. Cold Spring Harbor, NY: Cold Spring Harbor Laboratory.

SANGeR, F., NiCkLen, S. \& Coulson, A. R. (1977). DNA sequencing with chain terminating inhibitors. Proceedings of the National Academy of Sciences of the United States of America 74, 5463-5467.

Shaw, L. E. \& Williams, P. A. (1988). Physical and functional mapping of two cointegrate plasmids derived from RP4 and TOL plasmid pDK1. Journal of General Microbiology 134, 2463-2474.

SPOONER, R. A., LindSAY, K. \& Franklin, F. C. H. (1986). Genetic, functional and sequence analysis of the $x y l R$ and $x y l S$ regulatory genes of the TOL plasmid pWW0. Journal of General Microbiology 132, 1347-1358.

Wheatcroft, R. \& Williams, P. A. (1981). Rapid methods for the study of both stable and unstable plasmids in Pseudomonas. Journal of General Microbiology 124, 433-437.

Williams, P. A., Assinder, S. J. \& Shaw, L. E. (1990). Construction of hybrid $x y l E$ genes between the two duplicate homologous genes from TOL plasmid pWW53: comparison of the kinetic properties of the gene products. Journal of General Microbiology 136, 1583-1589.

Worsey, M. J. \& Williams, P. A. (1975). Metabolism of toluene and xylenes by Pseudomonas putida (arvilla) mt-2: evidence for a new function of the TOL plasmid. Journal of Bacteriology 124, 7-13.

Yanisch-Perron, C., VieIRA, J. \& Messing, J. (1985). Improved M13 phage cloning vectors and host strains: nucleotide sequences of the M13mp18 and pUC19 vectors. Gene 33, 103-119. 